\title{
Desencuentros en sociología estética Francisco Andrés Escobar, Centroamérica y el centroamericanismo
}

\author{
Rafael LARA-Martínez \\ Humanidades, Tecnológico de Nuevo México
}

Mi tesis [...] la llamé "Sociología estética" [...] habla y escribe en nombre del pueblo [...] usted es un poeta de las sensaciones y de los sentimientos [...] "en El Salvador, Monseñor Romero es el profeta nacional; Alfredo Espino, el poeta nacional”. FAE

Un pueblo (en la diáspora o no) se define siempre en términos de lugar (sea virtual o actual). El orden imperial, en contraste, no tiene nada que ver con esta dialéctica. El racismo imperial, o racismo diferencial, integra a los otros en su orden y luego orquestra esas diferencias en un sistema de control. Las nociones fijas y las biológicas de pueblo tienden así a disolverse en una multitud fluida y amorfa [...] la superficie de la sociedad imperial [...] desestabiliza la noción de lugar.

MH-AN

Si "la sociedad imperial [...] desestabiliza la noción de lugar", es de importancia vital definir la manera en que distintas teorías críticas 
analizan ese concepto. De inmediato nos sorprende que al corriente prevalece un interés por acentuar una idea de pérdida, por encima de todo rescate. Hibridez, falta de territorio (desterritorialización), carencia de identidad (posidentidad) y fluidez, son nociones más en boga que el de "lugar". Algunas teorías proponen recrear la vivencia de la comunidad a través del desarraigo. ¿Acaso entonces la mayoría de las teorías radicales actúan, sin saberlo, de acuerdo a la lógica del imperio? La ideología en boga - el posmodernismo- asienta el carácter descentrado y fluido de casi todos los conceptos operativos, de la realidad misma y de las identidades.

En efecto, la experiencia de la sociedad global, la que nos impone la actualidad económica, se corresponde con la existencia de redes flexibles. Las "relaciones estáticas" entre los individuos y el poder institucional tiende a fluctuar. A pesar de que la globalización no borra las fronteras sino para el capital y las mercancías, éstas se vuelven más porosas. La evidencia resulta de una realidad tanto más lacerante para aquellos países que, como El Salvador, cuentan con las remesas de "los hermanos lejanos" como un rubro vital de la economía nacional. Los valores rígidos de la "identidad nacional" se han conmovido.

Antes de los Acuerdos de Paz en 1992, hacia la década de los ochenta, las remesas constituían el dominio privilegiado de la entrada de divisas en el país. Alcanzaban más de un billón de dólares. Este apoyo financiero era suficiente para evitar que la crisis de la guerra se tradujese en desastre para la economía nacional. La "determinación económica" sentaba los fundamentos materiales para cualquier cambio político por venir. Incluso la esperanza de revolución se hallaba sujeta a esa flexibilidad financiera. La transferencia de capital desde los EEUU hacia el territorio nacional - la inmigración (i) legal hacia el nortecondicionaba toda nueva idea de identidad nacional. Mantenía el poder de reproducción social de la élite. Hoy en día, esta dependencia hace que la identidad sea no sólo un valor propio sino que también se halle sometida a una ley extranjera. Una dinámica entre lo propio y lo ajeno moldea el legado nacional.

Sin embargo, aunque ese vaivén sea cierto, el territorio como sentido de lugar sigue provocando fuertes atracciones en la diáspora. Esta determinación del terruño - “de tierra, cosa palpable”, diría Salarrué (2000) - juega un papel esencial al definir la identidad nacional salva- 
doreña. Esta es la tesis central que defiende Francisco Andrés Escobar en su libro La lira, la cruz y la sombra. Biografía de Alfredo Espino (2001). La tierra posee una materialidad tangible similar a la de la economía.

Lo más sugerente de su propuesta no es tanto resaltar la evidencia en sí. A la hora del capital global, un sentido arcaico del terruño orienta aún el significado de la identidad. Lo novedoso consiste en señalar tensiones. Hay conflictos latentes que sólo el porvenir podrá descubrir. Pero hay otros desencuentros que están a flor de piel. Aunque los ignoremos, establecen netas líneas divisorias de la época.

A ese contraste podemos referirnos bajo el nombre de contradicción entre teoría y práctica. Pero ahora que entramos de lleno al mundo posmoderno, al del capital global, lo llamaremos "desencuentro entre teoría estadounidense y arte latinoamericano". Este estruendo media la falta de diálogo entre el sujeto analítico del conocimiento racional y su "objeto", otro sujeto. Este último pone la experiencia, la intuición artística y la acción político al vivo; el primero interpreta la huella de esos hechos.

El choque convida a una teoría de la recepción y de la práctica de la escritura. Aunque leamos los mismos textos a ambos lados del Río Grande, la forma de captarlos no es la misma. Puede ser cierto que vivimos bajo la égida de la globalización. Pero, a pesar de que el capital ha impuesto su imperio a todo lo largo del globo, las fronteras aún pesan. Basta recordar el número creciente de deshidratados en el desierto de Arizona en 2002, para darnos cuenta de que la globalización no ha hecho desaparecer la cuestión nacional. Ni menos aún condensa la vida cotidiana en las distintas regiones del mundo. El análisis debe moverse entre lo concreto de la situación social en el Istmo y el imperio del capital global.

Aunque no aplicamos un análisis de tradiciones nacionales, asentamos que "el lugar de enunciación construido por los hablantes o escritores" divide la escena teórica en el continente (Mignolo, 122). El problema es 'tanto el acto de decir (y la audiencia involucrada) como lo que se dice (y el mundo referido)" (Mignolo, 128). Este es el caso del sitio que ocupan dos escritores de renombre: el argentino Jorge Luis Borges y el salvadoreño Alfredo Espino. Ambos han obtenido un reconocimiento notorio en su país de origen. Pero, mientras el prime- 
ro es lectura obligada en todos los departamentos de literatura y filosofía, el segundo es un desconocido fuera de su tierra.

En su justo juicio, en el extranjero, a nadie se le ocurre escribir una artículo sobre "el poeta nacional" salvadoreño. Ni siquiera los especialistas en Centroamérica se atreven a hacerlo. A lo más, en unas cuantas líneas, Espino es descontado como "poeta oficial de la dictadura". Esta es la tónica de las breves referencias a su obra en los EEUU. Por esta razón no nos extrañaría que nadie le preste atención a obra de Escobar fuera de la frontera nacional. Sin embargo, cuando las dictaduras decaen y el capital avanza, "la celebración del terruño" adopta un sesgo renovador (Escobar, 24).

A pesar de la nostalgia, el sentido de lugar, el que funda un "nacionalismo estético", puede revestirse de un carácter de resistencia (Escobar, 24). Ante la desintegración de las identidades "es más fácil comprender el valor progresivo de los [antiguos] modos de resistencia conservadores" (Jameson, 57). Escobar reclama que Centroamérica "es no sólo un área de estudio sino un lugar desde el cual se habla" (Mignolo, 123). En ese lugar - Cuzcatlán, El Salvador-asentaremos las sensaciones y la presencia de la historia como determinantes para entender el sentido del lugar.

Partiendo de un desacuerdo entre comentario racional extranjero y práctica literaria nacional, deseamos estudiar el libro La lira, la cruz y la sombra. Biografía de Alfredo Espino de Francisco Andrés Escobar. Pero antes de hacerlo, para contraponer su apreciación, nos es preciso delimitar el sitio ambivalente que se le ha otorgado a Borges en algunos estudios recientes sobre América Latina. La posición central del argentino en la renovación teórica del marxismo en los EEUU, es similar a la que lleva a cabo Escobar en su libro sobre el salvadoreño.

\section{De Borges, el neomarxista...}

La influencia de Borges en la filosofía radical no es nueva. Desde los años sesenta, muy lejos del ámbito estadounidense, en Francia, Michel Foucault lo utiliza como punto de partida en su libro Las palabras y las cosas (1968). Borges le sugiere al francés la idea de que las objetos en el mundo reciben un orden arbitrario a partir de las palabras. Las cosas no tienen un orden propio. El punto de mira del sujeto - su lengua, cultura, posición social- lo obliga a clasificar y 
ordenar los objetos de cierta manera particular. Foucault parte de la risa. Mientras resulta obvio de que la civilización china clasifica los animales de manera absurda - pertenecientes al Emperador, embalsamados, amaestrados, lechones, etc. - la clasificación occidental parece tan lógica que se juzga natural. Borges le enseña al francés a descubrir lo ficticio y lo arbitrario en el código occidental de clasificación del mundo.

Más recientemente Román de la Campa (1997) y Alberto Moreiras (2001) han descubierto en Borges el punto de mira para concederle un giro político a la crítica literaria latinoamericana en los EEUU. De la Campa reduce el entendimiento de las revoluciones centroamericanas y caribeñas a un texto del argentino: "Tlön, Uqbar, Orbis Tertius" (Borges, 13-34). Revela que un mismo folleto informa a César Augusto Sandino, a Farabundo Martí y al Che Guevara. Así como el mundo imaginario de Uqbar se equivale a "cuatro páginas adicionales" de "The Anglo-American Cyclopeadia", todas las revoluciones centroamericanas y del Caribe derivan también de un corto escrito común. El Nuevo Mundo de la utopía socialista nace de un mismo dicho del idioma.

El personaje clave es Alberto Bayo Giroud, un veterano de la Guerra Civil española. Por su presencia maestra, el mapa textual revolucionario se amplía de manera considerable. Abarca Europa y Africa, continente en el que Bayo Giraud luchó en varias sublevaciones. Bayo Giraud es autor del panfleto 150 preguntas a un guerrillero. Este libro lo escribe hacia los mismos años en que Borges elabora sus cuentos en Buenos Aires. En la actualidad, resulta curioso que este texto sólo se halle disponible en lengua inglesa en dos bibliotecas militares: la Central Intelligence Agency (C.I.A. en Washington, D.C.) y el U.S. Army Reserve Institute, Behavorial and Social Science (Virginia).

El libro sirve de puente entre la experiencia de Sandino, la de Martí y la cubana. El español realiza el escrito en 1939 en su país natal. Lo elabora en base a entrevistas que le concedieron algunos seguidores de Sandino en el exilio. El texto Bayo Giraud lo utiliza para entrenar a los hermanos Castro y al mismo Che en México, antes de su desembarco en Playa Girón, Cuba. Bayo Giraud es también quien inspira el clásico libro La Guerra de guerrillas del Che. Este último escrito lo ha utilizado la C.I.A. para formar comandos antiguerrilleros en la zona. 
De la Campa unfica así a "Borges, Che Guevara, Coronel Bayo, Sandino y Farabundo Martí" en su lucha común en contra de "generales despóticos, escuadrones de la muerte e intervenciones estadounidenses" (de la Campa, 39). Pone a la obra la enseñanza borgeana. Todas las revoluciones $-\mathrm{y}$ contrarrevoluciones - giran alrededor de un texto común. La "experiencia" misma no podemos recobrarla sino también a través de un texto original ahora inaccesible en su lengua original.

Pero esa unidad que De la Campa establece, por medio de Borges y de la difusión escrita del legado sandinista, es también una "ficción". En el estricto sentido borgeano, por "ficciones" se entiende "que un sistema no es otra cosa que la subordinación de todos los aspectos del universo a uno cualquiera de ellos" (Borges, 23). En efecto, aunque de la Campa haya obtenido la información sobre el nicaragüense del historiador estadounidense Donald C. Hodges, no hace referencia alguna a la mayor contribución del autor: el legado teosófico del "comunismo de Sandino". Hodges es autor de dos libros claves para entender la revolución nicaragüense, a saber: Intellectual Foundations of the Nicaraguan Revolution (Fundamentos intelectuales de la revolución nicaragüense, 1986) y Sandino's Communism. Spiritual Politics for the Twenty First Century (El comunismo de Sandino. Política espiritual para el siglo XXI, 1992).

De las dos obras, de la Campa sólo menciona la primera. La omisión nos da la pauta de su sistema de subordinación. En el segundo libro Hodges estudia documentos históricos inéditos. En esos materiales descubre que la fuente de inspiración del "comunismo de Sandino" es la filosofía oculta, la francmasonería y la teosofía. Como otros personajes de la época - Alberto Masferrer y Salarrué- Sandino funda un pensamiento utópico en base a un conocimiento esotérico. El silencio de esta corriente de espiritualidad le permite a de la Campa unificar todas las revoluciones del siglo. Ese silencio afecta también al desacuerdo radical entre Farabundo Martí, más cercano al marxismo, y Sandino.

La propuesta de agrupar todo el pensamiento revolucionario alrededor de un solo texto, el de Bayo Giroud, es más borgeana de lo que se piensa. Se trata de la "subordinación" de todos los "fundamentos intelectuales" del pensamiento utópico en el Istmo y en el Caribe - teosofía, indigenismo, cristianismo, ideas premarxistas va- 
rias y marxistas - al hecho guerrillero en sí. Dentro de la guerra de guerrilla, como al atardecer, todos los gatos son pardos. Todas las ideologías políticas se equivalen. Las ideas teosóficas de Sandino están "subordinadas" a su ideal revolucionario y guerrillero.

Si de la Campa unifica la experiencia guerrillera de la región a través de la "transcripción de la experiencia político-militar de Sandino", Moreiras deriva la teoría marxista de las ideologías también de una interpretación del escritor Jorge Luis Borges. Los relatos del argentino le ofrecen además una lectura de la sumisión de la sociedad occidental al imperio del capital, bajo los reglamentos keynesianos, primero, y del mercado, en seguida. Su propuesta central consiste en complementar la lectura filosófica de Borges con un acercamiento histórico.

El carácter profético de la intuición borgeana proviene de un antiguo adagio leninista: el eslabón más débil o el más deficiente (Moreiras, 163). Moreiras piensa que Latinoamérica ocupa un espacio marginal dentro del sistema capitalista global. Por tanto, ahí debemos buscar una respuesta profunda a las contradicciones de ese sistema. Siendo el eslabón más débil, en nuestro continente se agudizan sus deficiencias. De América, el cono sur es el más representativo, el más débil. Argentina, en específico Buenos Aires, y en particular Jorge Luis Borges exponen el sitio en donde se desglosa un pensamiento radical sobre el modo de producción de sujetos bajo el poder del capital.

Como en De la Campa, el silencio nos da la pauta de una paradoja que impulsa a Moreiras. Su idea del estado keynesiano — de la sumisión de todos los aspectos sociales al capital - la retoma de los autores que inicia este artículo: el estadounidense Michael Hardt y el italiano Antonio Negri (2000). Sin embargo, la tesis del eslabón más débil"al centro de las tácticas de la Tercera Internacional"-es contraria al movimiento obrero que impulsa el italiano. Por lo contrario, Negri defiende el "eslabón más fuerte" (Hardt y Negri, 428). Hardt y Negri suponen que el capital regula un sistema global de sometimiento de todos los aspectos sociales e individuales. Se trata de una regla universal sin excepción. No hay nada que le escape y, por tanto, no existe ningún elemento que se sitúe por fuera del sistema global de control que impone el capital. Este dicta también nuestros sueños.

Sin notarlc, esta última tesis da cuenta del pensamiento de Moreiras. En verdad, Argentina y Buenos Aires no se corresponden con el "es-

Desencuentros en sociología estética 
labón más débil". A menos que se demuestre que en ese país la pobreza, el desarrollo desigual, el "subdesarrollo", es mayor que en Guatemala, Honduras o República Dominicana. Moreiras debe demostrar entonces la existencia de autores similares a Borges, no en un lugar privilegiado de los más débiles: Buenos Aires. El reto que esta constancia le presenta es descubrir escritores de ese rango en los sitios más “débiles' del sistema capitalista global. Argentina representa el "eslabón más fuerte" dentro de los débiles.

El texto clave es "La lotería de Babilonia" (Borges, 57-66). Según Moreiras, este cuento "es una de las fuentes teóricas para la noción althusseriana de ideología” (Moreiras, 179). Relata los cambios que sufre la sociedad capitalista mundial en la década de los treinta. Narra la historia de una "Compañía secreta" a la cual nadie puede escapar. La sociedad entera debe someterse a sus designios. Incluso los destinos personales, los sueños y el inconsciente los dirige la Compañía. Moreiras asienta que la lotería es una metáfora del mercado. Este regula y planifica todos los aspectos de la vida social.

A partir de la depresión de 1929, nace el estado keynessiano. Las ideas del laissez-faire, del libre cambio y del mercado caen en desuso. El estado no garantiza únicamente el orden público. En cambio, actúa en la economía y la planifica. Interviene en asuntos monetarios y en la reglamentación de las transacciones mercantiles, antes de ceder frente a la presión de la "lotería", del mercado global. Poco a poco, la "lotería" absorve las decisiones del estado. Aunque se mantienen las fronteras nacionales, el estado se vuelve una simple sucursal de las corporaciones transnacionales. Hoy en día es una mera unidad administrativa y comercial. "La lotería" - la fluidez del capital - se convierte en "el todopoder" exclusivo (Borges, 59). Invade la "suma del poder público" (Borges, 60).

El caso más singular de esta absoluta determinación, es la experiencia del propio teórico marxista francés, Louis Althusser. La mañana del domingo 16 de noviembre de 1980, literalmente, lleva a la práctica el cuento de Borges. Inconsciente estrangula a su mujer, aplicando a la letra el dictado del argentino: "el soñador que se despierta de golpe y ahoga con las manos a la mujer que duerme a su lado" (Borges, 65). Así, ni siquiera la teoría crítica más radical se halla por fuera de la determinación del capital. La Compañía rige los sueños de la renovación del marxismo. La utopía obedece al régimen del capital.

\section{4}

Realidad 92, 2003 
Esta sería la conclusión lógica. Sin embargo, Moreiras se permite un tour de force intempestivo. Como buen materialista, apela al Mesías. La "traza mesiánica" define el instante en el cual el "pensamiento occidental" abre la "posibilidad de una reflexión del exterior" (Moreiras, 41). Se trata de una "necesidad" intrínseca al sistema mismo de imposición de una sociedad global. Esta necesidad crea una "abertura" que "se vuelve una región salvífica o redentora" (lugar citado). Aunque descalifica al realismo mágico como posibilidad de ocupar un sitio dentro de esa esfera, Borges y el marxismo se localizan, por lo contrario, en el centro mismo de ese espacio mesiánico. Acaso este llamado al Mesías sea la segunda paradoja de Moreiras. El marxismo sólo se ofrece como alternativa utópica si articula antiguas ideas milenarias.

De nuevo, como en el caso del eslabón más débil —situado en el "París de Sur América" - el privilegio se presta a la polémica. Al marxismo se le asigna un sitio de privilegio en la "región salvífica". A pesar de la "locura" de su renovador, el marxismo se ofrece como la única "ciencia de las contradicciones inherentes al capitalismo" (Jameson, 164). Pero el realismo mágico, en cambio, queda descalificado como simple "ideología". El suicidio del peruano José María Arguedas es el síntoma de su descalabro. La cuestión que Moreiras deja abierta es indagar por qué, dentro de la "locura" althusseriana, el marxismo borgeano queda intacto, mientras en la irresolución de Arguedas se señala el fin de un sistema literario.

Por realismo mágico, Moreiras entiende un estilo artístico en el cual entran en juego dos modos de producción, uno precapitalista y otro capitalista. En esa arena artística se contraponen visiones del mundo distintas, una tradicional y otra moderna. El primero de esos universos sociales actúa de acuerdo a una lógica animista y religiosa. El medio ambiente aún no ha sido desacralizado. Posee la huella de lo "mágico" y de la inocencia. Los dioses de antaño, los tonalli o nahuales, o bien las huaca en Arguedas pueblan el entorno. El mundo carga el poder sagrado de las potencias místicas. Frente a esta sacralización del terruño, la modernización se presenta como una fuerza destructora, desacralizadora. Movida por el afán de lucro y por una creciente racionalización, las fuerzas mágicas pierden su encanto. La tecnología y la explotación comercial de los recursos naturales fijan los límites para la modernidad. Ahora vivimos en el desencantamiento del mundo. La modernización significa la pérdida del carácter mágico del entorno. 
Este choque produce un amplio conflicto social y un desgarramiento cultural. En nadie más que en Arguedas se expresa la consciencia trágica de esa destrucción desacralizadora. En su novela póstuma que le cuesta la vida, El zorro de arriba y el zorro de abajo (1971), Arguedas representa el estruendo entre el Perú mestizo de la costa y el indígena de los Andes, por medio de dos figuras míticas o buacas, los zorros. No obstante, la novela no relata sólo el estruendo que se produce por el choque violento entre esas dos caras del Perú. A la vez, Arguedas intercala su inestabilidad emocional y la dificultad creciente por escribir la novela.

Su decisión de suicidarse concluye el relato novelesco truncado. Ahí asienta no tanto los problemas de su psique personal torturada. Anota en cambio un hecho social. Se trata de la imposibilidad del mestizaje latinoamericano. La modernización no genera un diálogo entre los zorros. Por lo contrario, en el espacio narrativo de Chimbote - pueblo donde ocurre la novela- lo indígena cede ante el embate de lo moderno. Lo que existe es un proceso despiadado y violento de incorporación al capital global.

Arguedas cae en la cuenta de que incluso los zorros carecen de sentido. En el mundo tecnológico moderno, industrializado, los dioses están muertos. La magia andina no puede traducirse sino en un recurso comercial para el mercadeo de la novela. Ahora que todo es negocio, por el procedimiento de intercalar la magia al centro de lo moderno, la voz indígena alcanza los circuitos de difusión internacional. Pero, paradójicamente, alcanza esos circuitos en el momento en que las corporaciones transnacionales se encargan de desacralizar el mundo. Incorporan la sociedad andina a lo moderno, por un proceso de proletarización forzado. Como en el cuento "La lotería de Babilonia", el mercado y el capital absorven y dominan el mundo tradicional.

Arguedas representa el momento en que se desglosa la consciencia de la imposible reconciliación entre lo moderno y lo indígena. No hay diálogo, sino imposición brutal del proyecto de modernización. Su suicidio marca el fin de una ilusión. Sólo por medio de un acto de violencia, el arte y, en específico, la literatura latinoamericana, el realismo mágico, puede apropiarse de lo indígena. En un mundo desencantado por la modernización, lo mágico ha muerto. 
Moreiras presupone que el desencantamiento del mundo es una visión compartida universalmente por todos los estratos sociales. Es paralela a la globalización del capital. Esta cuestión, veremos, resulta polémica. No puede haber racionalización absoluta si una "traza mesiánica" persiste en la memoria. "Una región redentora" permanece vigente. Lo "mágico" del realismo marxista de Moreiras -el borgeano- lo hallamos en la presencia utópica del Mesías en su pensamiento crítico laico.

Quizás la conclusión de Moreiras sería la siguiente. Mientras los mitos decaen, el capital asciende y, por tanto, el estudio de sus contradicciones - a pesar de la locura althusseriana- está a la orden del día. Dejamos sin resolver porqué la escritura borgeana es más relevante para conocer el presente que la denuncia, la solidaridad y el combate de cientos de militantes. Sin la necesidad de un compromiso político directo, la complejidad del pensamiento borgeano anticipa la actualidad. Por eso, Borges está al lado de los grandes teóricos del (neo)marxismo: Althusser, Hardt, Jameson, Negri, Roger Bartra, Michael Taussig, etc. En dado caso, no basta denunciar dictaduras ni defender derechos humanos, hay que alcanzar una compresión adecuada de lo real.

\section{2. ... A Espino, "el poeta nacional"}

La memoria del poeta muerto se fue afirmando cada vez más en la conciencia de todos [...] y se enraizó más, cuando las rachas de violencia mandaron al exilio a tantos hombres y mujeres que debieron establecerse en otras tierras, mientras dejaban el alma plantada aquí. Entre sus escasas y apresuradas maletas de viaje, cargaban algún ejemplar gastado de las "Jícaras". Así se llevaban los vientos y los pericos de esta tierra. FAE

De aplicar a la ligera las ideas de Moreiras, podemos descubrir un descalabro semejante en Centro América. Si el suicidio de Arguedas marca el límite de la antropología literaria en Latinoamérica, un acontecimiento trágico similar recorta el regionalismo salvadoreño. El suicidio de Alfredo Espino es el acta de defunción de esta última corriente artística. La conclusión resulta tanto más paradójica cuanto que, antes de llegar a su apogeo con la obra de Salarrué, Espino le había propiciado el tiro de gracia al regionalismo. 
Este argumento resalta con mayor evidencia en los poemarios que culminan el único libro del autor, Jicaras tristes (1936). Hacia el final de la obra, la evocación del terruño se vuelca hacia el ambiente urbano de los barrios bajos y de las barriadas. El arte regionalista reconoce ahí su inevitable origen y destino urbano. Acaso Espino insinúa la destrucción del medio ambiente, la de lo rural, y su disolución en la marginalidad urbana. La ciudad desgasta el antiguo encanto campestre.

No obstante, Escobar nos revela que una función social insospechada recubre la poesía costumbrista de Espino. Sea que describa el paisaje e idealice el mundo campesino, sea que se diluya en la vida citadina, la poética inaugura el camino hacia una "región salvífica y redentora". Piensa la utopía del arraigo y de la identidad, a pesar del destino imperial por lo híbrido y la desidentidad. Escobar sugiere un desencuentro radical. Aunque los centroamericanistas se niegan a leer la obra de Espino, su poesía define la identidad salvadoreña con mayor intensidad que los escritores nacionales, consagrados en lengua inglesa en los EEUU. A la hora del capital global, cuando el desarraigo está a la moda, hay algo que no muda: la identificación con el terruño.

La prueba tangible de esa "traza mesiánica" son los millones de dólares que la diáspora salvadoreña envía a su país de origen. Las remesas demuestran el arraigo y la identificación con los familiares y con la tierra. De ahí que, al fortalecer la identidad, la función "redentora" de Espino sea la de minar la determinación del imperio. Su poesía mantiene viva filiaciones primarias que al nuevo orden imperial le corresponde disolver.

La tesis de Escobar se mueve a contracorriente del silencio de los centroamericanistas con respecto a Espino. El poeta regionalista fue quizás el artista de la dictadura militar, en la primera mitad del siglo XX. Pero en la posguerra, su sitio cambia de manera radical. Escobar historiza la lectura de Espino. El argumento tradicional se desmorona por su falta de referencia. Ahora ya no hay dictadura. Los militares no avalan a Espino. Los propios lectores salvadoreños encuentran en su simplicidad una manera de recobrar "sensaciones" y "sentimientos" de "raíz agrícola” e infantil (Escobar, 15 y 17). Las cualidades sensibles los remiten a la tierra de infancia, al origen. La renovación del regionalismo no la propone el estado ni el ejército. La efectúa la posición intersubjetiva de sus propios lectores. Aunque la crítica profesional reniega de Espino, el lector común y corriente lo consagra. Vindica en 
él un lazo de identidad ante la disolución posmoderna de todo amarre con el origen.

Espino fundamenta la solidez de un arraigo en un espacio-tiempo específico en el mundo. Representa no tanto una reconciliación del exiliado con la historia nacional; en cambio, expresa el retorno imaginario al lugar mismo que sustenta la historia: el espacio-tiempo de Cuzcatlán. Una lectura crítica de Espino complementa la teoría testimonial. Mientras esta última nos ofrece una verdad al desnudo, una visión de la violencia de la historia, la primera exhibe el reverso de la medalla (sobre el marxismo como una visión radical de la historia, pero que preserva una perspectiva conservadora del tiempo, véase: Agamben, 1978: 83-112).

No hay historia sin espacio-tiempo. La violencia siempre se lleva a cabo en un lugar. Ahí residen los muertos, los desaparecidos y los antepasados. Contrario al designio imperial —que comparte la teoría testimonial en su silencio- Espino ofrece un sentido estable de la noción de lugar. iCuzcatlán, El Salvador! Esa es la morada de la historia, el camposanto en que reposan los ancestros. Como en toda "semiosis colonial", el lugar dicta los parámetros para entender cómo "el sujeto percibe la situación [y] en cuáles tradiciones culturales se localiza el sujeto" (Mignolo, 126).

El lugar posee una textura sensorial y una abertura hacia el pretérito. Sólo una estética (del griego aisthesis, la esfera de la sensación y percepción humana) es capaz de recobrar la significación del lugar (véase al respecto el análisis que hemos propuesto de la obra de Salarrué: Lara Martínez, en prensa). Las cualidades sensibles de las cosas - color, olor, sabor, sonido y textura - fundan una medida subjetiva del espacio-tiempo. No hay lugar sin la mirada (inter)subjetiva de una sociedad hacia el entorno.

Al grupo humano le corresponde privilegiar ciertas cualidades sensibles del medio ambiente para interactuar con el mundo y fundar un sentido. Tal como lo declara el cubano José Lezama Lima "lo único que crea cultura es el paisaje [...] haciéndose [= la naturaleza] paisaje por el nuevo idioma [ = la poesía regionalista de Espino] que [la] recorre" (Lezama Lima, 434). Confirma que la cultura nace del paisaje, de la tekhne humana en su relación con el mundo. 
Pero al dar cuenta de esa estética, Escobar no renuncia a la esfera del arte. Por lo contrario, el libro demuestra que sólo al arte se le permite hablar del arte. Forma y contenido se entremezclan en una unidad indisoluble. Por eso, las seis secciones que componen el libro adoptan un enfoque poético extremo. En ellas, de nuevo, Escobar actúa a contracorriente del desencantamiento del mundo contemporáneo, del centroamericanismo. Opta por resacralizar el mundo. $\mathrm{O}$, quizás para el escritor, el mundo nunca se ha visto afectado por el desencantamiento posmoderno. Esta absoluta racionalización Moreiras presuponía que era universal, si bien mantenía viva la esperanza en el Mesías.

Las seis secciones del libro exhiben una riqueza de recursos de estilo. En la primera, "El poeta nacional", Escobar entrevista al escritor difunto, como si el alma de Espino vagara aún en la capital salvadoreña. En la segunda, "La ciudad del poeta", recrea la vida diaria en San Salvador en la primera década del siglo XX. La descripción novelada adopta la forma de una hermosa prosa poética, movida por la presencia activa de los autores de la época. En la tercera, "La lira, la cruz y la sombra", surge el drama familiar de los padres de Espino. Ellos indagan las causas del suicidio: incompresión social frente a la creación y sensibilidad artística, posesividad del superego materno, conflicto con el padre, identificación con la marginalidad social, etc. En la cuarta, "Diarios del poeta", Escobar se reviste con la personalidad artística de Espino y, como poeta poseso, rescata fragmentos del pasado. En la quinta, "Anexos históricos", de manera más objetiva, recoje las reacciones de los intelectuales de la época, frente a la trágica muerte del poeta. Por último, en el corto "Epílogo", el propio Espino se hace presente, resucita y promueve el valor de la obra que el lector tiene en sus manos.

Los distintos recursos poéticos invocan la presencia de los muertos. Una estética de Cuzcatlán transcribe un testimonio de la historia. La interpretación e historiografía literaria no se definen como un acto objetivo de rescate de documentos y su lectura racional. En cambio, se trata de una consulta de la experiencia subjetiva de los antepasados difuntos. Los ancestros moran en el entorno.

La distancia con el "paper" académico no puede ser mayor. Mientras Escobar se mueve en un mundo artístico poblado de "almas en pena" - para usar una expresión rulfeana- el comentario académico 
apela a una racionalización absoluta. En efecto, tal como lo ha demostrado Fredric Jameson en su artículo "'End of Art' or 'End of History'? ('FFin del arte' o 'fin de la historia'?)", un cambio profundo afecta el papel del arte en la posmodernidad. En el mundo actual, el arte ha llegado a su "fin"; en el de Escobar, el arte es aún posible.

Según Jameson, a partir de la década de los sesenta, se completa una antigua intuición hegeliana. "Para nosotros el arte no cuenta como el modo más alto por el cual la verdad recobra la existencia”" (Jameson, 82). El arte ya no prepara la vía por la que la verdad transita hacia la vida. Desde entonces, se produce una confusión de áreas de estudio. Todo se vuelve cultura y la cultura, a su vez, se vuelca sobre "lo económico" y se orienta hacia la producción de "mercancías" (Jameson, 73).

Se intensifica la comercialización del arte. La complejidad artística moderna - lo sublime - da lugar a lo hermoso, mejor dicho, a "lo bonito", y a una función puramente decorativa de la obra. Entramos de lleno en la posmodernidad. Vivimos en un mundo colonizado por la imagen, por el espectáculo televisivo y, en fin, por la conversión del arte en mercadería.

Al mismo tiempo, los sistemas artísticos de la modernidad se diluyen en la filosofía. Se opera el clásico "movimiento" hegeliano hacia la realización del "espíritu absoluto" (Jameson, 76). Esta "progresión" se expresa en la "tríada": "religión, arte y filosofía" (lugar citado). Es así que "la Teoría [...] suplanta la literatura tradicional desde los sesenta" (Jameson, 84). "Lo sublime, lo moderno" se realiza en la sistematización teórica, mientras "lo bonito y decorativo (the light, the nice and cute)" invade el terreno del arte en sí. Las innovaciones artísticas se confunden con la propaganda comercial, con el negocio.

Dentro de este esquema, el papel "redentor" del arte moderno se desplaza hacia el "paper" académico. ¿Acaso no es ahí que culmina el arte? Incluso la literatura de protesta y el testimonio, encuentran en el ensayo de corte universitario la máxima expresión de su contenido mesiánico de denuncia. "La meta fija del pensamiento latinoamericanista" consiste en "preservar y realizar las experiencias latinoamericanas que detendrían "el encierro total del mundo por el orden dominante"” (Moreiras, 43-44). El fin de esa reflexión, en el ensayo acadé-

Desencuentros en sociología estética 
mico, es inscribir la "traza mesiánica" llamada Latinoamérica -lo exterior a lo global- en el medio de la filosofía occidental.

Pero, precisamente, Escobar rechaza este esquema que desintegra el arte en el ensayo. No desprecia el contenido social de la poesía. Por lo contario, lo reivindica: a la poesía le corresponde mantener una identidad nacional, a la hora de la híbridez y del desarraigo. La poesía posee un neto valor de resistencia. Frente a la fluidez del capital global, a la migración creciente, la lectura de Espino propicia la conservación de un valor estable. Desde la premodernidad se afirman sensaciones primarias, irracionales, que ligan a los individuos dispersos a su comunidad de origen y a la historia, a los muertos.

Así lo anota el estadounidense Gareth Williams: "los circuitos transnacionales $[\ldots]$ no significan el fin de la historia, ni de la actualidad, de la nación. La migración salvadoreña masiva [...] no denota el fin del significante El Salvador [...] lo nacional e incluso la noción de lo nacional popular circulan a manera de espectro como sitios inquietantes (baunting) de la experiencia colectiva" (Williams, 144). El dominio de lo sensorial -la poética de Espino, añadiría Escobar- constituye una de esas obsesiones "fantasmagóricas" de la memoria común. Las sensaciones del terruño "embrujan" aún a los migrantes. Esa percepción revive a los muertes.

El papel de identificación sensorial presupone una distinción adicional. No es lo mismo "bablar de Centroamérica" que "bablar desde Centroamérica" (la distinción la establece Mignolo). Mientras el "bablar desde" desarrolla una estética en la cual las sensaciones mismas del escritor se ballan en juego, el "bablar de" hace abstracción de la percepción inmediata. A menos, por supuesto, de ser inmigrante. La racionalidad del análisis suplanta a la vivencia. El "bablar desde" define, en cambio, un testimonio afectivo de la vivencia sensorial.

Dejamos abierta la cuestión de saber si la racionalización que exige el "paper" no se compagina con uno de los conceptos claves de la expansión del capital a todo lo largo del globo: la "reificación (cosificación)" (Jameson, 2000: 117-118). Tal como el concepto lo define el Webster's New Universal Unabridged Dictionary of the English Language (1983: 1523), la palabra proviene del latín "res", "cosa" y de "-fy,- ficare", "hacer, producir": "cosificar, hacer semejante a una 
cosa". Significa "tratar una abstracción como substancialmente existente, o como un objeto concreto material".

Mencionamos que el estudo de la historia tendía a desgajarse del lugar, del espacio-tiempo en que ocurre. Ahora damos constancia de que las sensaciones primarias también se abstraen del análisis. ¿Acaso entonces no nos situamos en un sitio borgeano clásico? Ahí donde de la rosa (del objeto sensitivo material) no queda sino el nombre de la rosa sin rosa. ¿El Salvador, por fuera de la percepción inmediata de los cinco sentidos?

De nuevo Jameson apoya el análisis al informarnos que "los paisajes móviles" de Cuzcatlán crean "un espacio heterogéneo" (Jameson, 64). La "multiplicidad de niveles" en esos paisajes "ya no pueden asimilarse a [...] las reificaciones (cosificaciones) y represiones de lo conceptual o de lo racional estrecho" (lugar citado). Pero esa valorización de la riqueza sensorial surge como reacción a "la gradual colonización del mundo por la homogenización" (Jameson, 65).

La estética de Espino marca el momento en que un "sistema occidental" de tenencia privada de la tierra sustituye los antiguos valores indígenas y comunales. Sin ser tan categóricos, así lo habíamos asentado en un antiguo artículo sobre Espino, al cual Escobar hace referencia (Lara Martínez, inédito; Escobar, 20 y 135). El "edén subvertido" es la visión que la ciudad nos otorga del paisaje y del campesinado. Espino es el portavoz del despegue económico, del inicio de la urbanización en el país. Su medida concreta de la estética, es el reverso imaginario de la especulación urbana sobre la tierra. La urbanización provova "el volverse abstracto de todo terreno y de la tierra". Espino nos enseña la otra cara "de la globalización" (Jameson, 154).

Al rechazar la "reificación (cosificación)" del objeto sensible, Escobar apela no sólo a una estética que se arraiga en los sentidos, en las sensaciones inmediatas del lector. Más aún, recobra una historia poblada de personajes, de anécdotas y de vivencias funerarias. Hace hablar a los muertos. Los evoca y les concede una voz. Los difuntos poseen una realidad tangible como la materia. La historia está viva en el lugar. Escobar crea así un verdadero testimonio del pasado. Tal como lo ha definido el filósofo italiano Giorgio Agamben, sólo al otorgarles la voz a los muertos, el testimonio puede colmar "una laguna" (Agamben, 1999: 33). Este trecho vacío es el siguiente: "quienes 
no han vivido la experiencia no la conocen; quienes la han vivido no la cuentan; no realmente, no completamente... El pasado pertenece a los muertos" (Agamben, lugar citado).

En la propuesta de Escobar, quienes no han sentido el olor, el sabor, el color, el sonido y la textura de El Salvador, quienes no han entrevistado a los muertos, no lo conocen. A lo más, saben mucho del tema. El conocimiento sensorial de un grupo humano y el saber sociológico no siempre van de la par. Esta laguna se ensancha ahora que la historia se ha vuelto "estática", en el único sistema económico imaginable, y que es imposible pensar las "muertes individuales" (Jameson, 60-61).

En el lugar, Escobar colma ese trecho entre conocer y saber. Al "hablar desde" aún es posible darle la voz a los muertos. Hay que interrogar a los testigos de la historia. La contrapropuesta es simple, pero radical. Escobar y sus lectores - los lectores de Espino- viven en un mundo sacralizado. En el lugar de origen, los muertos hablan. Williams está consciente de que ese núcleo mágico, mesiánico, se halla presente en Los Angeles. Refiere que "los muertos siempre regresan a perturbar/embrujar (baunt) a los vivos [...] el linaje de los ausentes (el FMLN) y la sociedad de los vivos (la "Calle Dieciocho") existen aliados como imágenes recíprocas en el espejo" (Williams, 157). Apenas un hilo tenue separa vida y muerte, unidas desde siempre en el lugar.

Se califique de nostalgia o de reticencia conservadora, lo cierto es que esa visión sacralizadora del lugar actúa en contra de los designios del imperio. Es una activa resistencia ante los procesos de desintegración. Ante la fluidez del capital, de lo híbrido y de las identidades cambiantes, en su cándida melodía, "la celebración del terruño" supone un movimiento de resistencia pasivo y de estabilidad.

¿Mantener la identidad en un mundo sin sentido? Quizás en todo lugar existe una "traza mesiánica" — una esfera sagrada— imposible de colonizar y de desacralizar. ¿Borges y Espino como regiones salvíficas? Incluso el materialismo más radical —el dialéctico- apela al Mesías. Funda un lugar. Quizás porque la utopía es eso: la llegada del tiempo mesiánico. El imposible retorno a Cuzcatlán... (1) 
1. Dejamos sin explorar lo que sería una crítica posmoderna a la propuesta de Escobar. Tal como lo asienta el colombiano Santiago Castro-Gómez en Crítica de la razón latinoamericana (1996: 75), "el recurso a la influencia de la tierra, el paisaje y la naturaleza sobre las formas culturales, es uno de los motivos más apetecidos por los discursos de la identidad". En la actualidad, se trata de "reacciones defensivas" frente a la globalización (Castro-Gómez, 47). La búsqueda de un "fundamento viltimo a partir del cual se pueda distinguir lo auténtico" presupone tres premisas: un "mesianismo salvacionista", una "exclusión de las diferencias" y una "alteridad con respecto a la modernidad” (Castro-Gómez, 94-95). En primer lugar, Escobar invoca a "los representantes" del alma popular - Romero y Espino- como "prioridad política" para "superar las taras", olvidando que "los pensadores [...] asumieron la "misión" de producir ideologías y políticas culturales destinadas a reglamentar la vida pública" (Castro-Gómez, 115). Luego, diluye toda diferencia de edad, sexo, clase y etnia en un "nosotros" homogéneo". Por último, este "ser salvadoreño" único, abstracto, sirve de pauta para postular la distinción con respecto a un "ellos" quienes no comparten una sensibilidad semejante por el terruño. Castro-Gómez propone sustituir la búsqueda de figuras y la de un fundamento original, por una "historia de la producción de esa verdad" (Castr-Gómez, 95). Si demostramos que el mesianismo y la fundación de un lugar permea también al neomarxismo, queda abierta a la discusión la manera en qué un giro hacia analizar el proceso de formación del origen repercutirá en la creación de nuevos movimientos sociales.

\section{BiBLIOGRAFÍA}

Agamben, Giorgio. Enfance et histoire. Destruction de l'expérience et origine de l'histoire. Paris: Editions Payot, 1978.

-.Remnants of Auschwitz. The Witness and the Archive. New York: Zone Books, 1999.

Arguedas, José María. El zorro de arriba y el zorro de abajo. Buenos Aires: Editorial Posada, 1971.

Borges, Jorge Luis. Ficciones. Buenos Aires: Emecé Editores, 1956.

Castro-Gómez, Santiago. Crítica de la razón latinoamericana. Barcelona: Puvill Libros S. A., 1996.

de la Campa, Román. Latinoamericanism. Minneapolis: U. of Minnesota P., 1997.

Escobar, Francisco Andrés. La lira, la cruz y la sombra. Biografía de Alfredo Espino. San Salvador: Dirección de Publicaciones, 2001.

Espino, Alfredo. Jicaras tristes. San Salvador: Talleres Gráficos Cisneros, 1936.

Foucault, Michel. Las palabras y las cosas. México: Siglo XXI Editores, 1968. 
Hardt, Michael and Antonio Negri. Empire. Cambridge: Harvard U. P., 2000.

Hodges, Donald C. Intellectual Foundations of the Nicaraguan Revolution. Austin: U. of Texas P., 1986.

-. Sandino's Communism. Spiritual Politics for the Twenty First Century. Austin: U. of Texas P., 1992.

Jameson, Fredric. "The Antinomies of Postmodernity". The Cultural Turn. Selected Writings on the Postmodern, 1983-1998. London/ New York: Verso, 1998: 50-72.

- ."'End of Art' or 'End of History'?". The Cultural Turn. Selected Writings on the Postmodern, 1983-1998. London/New York: Verso, 1998: 73-92.

-. "Culture and Finance Capital". The Cultural Turn. Selected Writings on the Postmodern, 1983-1998. London/New York: Verso, 1998: 136-161.

—."On Jargon". Michael Hardt and Kathi Weeks (Eds.), The Jameson Reader. Oxford: Blackwell Pub., 2000: 117-118.

- "Five Theses on Actually Existing Marxism". Michael Hardt and Kathi Weeks (Eds.), The Jameson Reader. Oxford: Blackwell Pub., 2000: 164-171.

Lara Martínez, Rafael. "Salarrué. Estética, picaresca y recreación del vernáculo". América Rodríguez (Ed.), Las identidades de El Salvador. San Salvador: Editorial Delgado, en prensa.

-. "Alfredo Espino. El sino trágico de la pastoral salvadoreña". Inédito.

Lezama Lima, José. El reino de la imagen. Caracas: Editorial Ayacucho, 1981.

Mignolo, Walter D. "Colonial and Postcolonial Discourse: Cultural Critique or Academic Colonialism". Latin American Research Review, 28, No. 3, 1993: 120-134.

Moreiras, Alberto. The Exhaustation of Difference. The Politics of Latin American Cultural Studies. Durham: Duke U. P., 2001.

Salarrué. "Mi carta a los patriotas. 21 de enero de 1932". La Prensa Gráfica, Mayo de 2000.

Webster, Noah. Webster's New Universal Unabridged Dictionary of the English Language. New York: Dorset \& Baber, 1983.

Williams, Gareth. "Subalternity and the Neoliberal Habitus: Thinking Insurrection on the El Salvador/South Central Interface". Durham, NC: Nepantla: Views from the South, 1.1, 2000: 139-170. 